\title{
Malignant meningitis: a rational approach to cerebrospinal fluid cytology
}

\author{
J M MacKenzie
}

\begin{abstract}
Aim-To clarify laboratory guidelines for cerebrospinal fluid (CSF) cytology.

Methods-Clinical and pathological data relating to 54 patients with cytologically malignant cells in the CSF were reviewed, together with CSF cell counts and protein measurements for 29 patients. Utilising this data, criteria were established for CSF cytology and validated by review of 100 patients in whom CSF cytology had not been carried out on the basis of these criteria.
\end{abstract}

Results-There was only one false positive diagnosis of malignancy on the basis of CSF cytology. All patients with malignant cells in the CSF fulfilled at least one of the following criteria: clinically known or suspected malignancy; raised cell count; raised protein concentration. In none of the 100 patients, in whom cytology was not performed, was the diagnosis of malignant meningitis missed.

Conclusion-Cytology should be performed on CSF specimens from all patients with known, or suspected, malignancy, but in other cases, only if the cell count or protein concentration, or both, is raised.

(F Clin Pathol 1996;49:497-499)

Keywords: malignancy, cerebrospinal fluid, cytology.

Various attempts have been made to establish guidelines for laboratory examination of cerebrospinal fluid (CSF). ${ }^{12}$ Physician microscopy of CSF samples with normal cell counts has been shown to be unnecessary and wasteful of resources. ${ }^{3}$ Furthermore, if the opening pressure, cell count and protein concentration are all normal, additional procedures are rarely of value. ${ }^{4} \mathrm{CSF}$ cytology is principally useful in the identification of malignant cells, as the cytological changes in inflammatory and other non-neoplastic disorders are non-specific. ${ }^{56}$

The progress of non-neoplastic conditions can be monitored by CSF cell count/ differential, protein and glucose concentrations measured by a biomedical scientist without the necessity of the use of expensive pathologist's time in performing cytology. Suspected infections require proper microbiological investigation of the $\mathrm{CSF}^{6}$ and identification of organisms in a cytological preparation is probably only an aesthetic reward for the pathologist and contributes little, if anything, to the patient's management. Yet clinicians frequently adopt the "blunderbuss" approach to request- ing of laboratory tests on CSF without due regard to the propriety of tests in the clinical circumstances, with cytology, cell count, protein, glucose, oligoclonal bands, and microbiology often being requested routinely, and pathologists often feel a moral obligation to carry out the tests requested, even if this has no rational basis.

This study sought to clarify criteria by which the pathologist can decide when CSF cytology is likely to contribute to the patient's management, and minimise the number of unnecessary cytological tests, firstly, by defining under what circumstances malignant cells are likely to be found in the CSF and, secondly, by validating these criteria in practice.

\section{Methods}

From 1980 to 1990 , cytology was carried out on all CSF specimens received in the Neuropathology Laboratory of the Walton Centre for Neurology and Neurosurgery, Liverpool. During that period 5808 cytological specimens were received. All of the reports were reviewed and, in CSF samples from 132 patients, cells variously described as "malignant", "atypical" or "suspicious" had been described. All of the cytospin preparations from these patients were re-examined and CSF samples from 54 patients contained cells which were regarded as definitely malignant.

The clinical details and histological material (where available) relating to these 54 patients were reviewed in order to (1) confirm that the diagnosis of malignancy on the basis of CSF cytology was correct and (2) identify criteria by which the decision whether or not to perform cytology could be made in the laboratory. To assist in the second objective, cell counts and protein concentrations, available for 29 of the patients, were also utilised.

Having established, and implemented, the criteria 100 cases from 1992 to 1993 for which complete clinical records were available, and in which cytology had not been carried out on the basis of these criteria, were randomly selected and thoroughly reviewed to establish whether there was any possibility that a case of malignant meningitis had been missed.

\section{Results}

ACCURACY OF CYTOLOGICAL DIAGNOSIS

Fifty of the 54 patients with malignant cells in the CSF had confirmed malignancy, either known at the time of CSF sampling (43 patients) or subsequently confirmed by clinical, radiological or pathological investigation (seven patients). Of the remainder, three were 
Table 1 Types of malignancies

\begin{tabular}{ll}
\hline Malignancy & Number (\%) \\
\hline Carcinoma & $25(50 \%)$ \\
Breast & 11 \\
Lung & 8 \\
Gastrointestinal tract & 3 \\
Genitourinary tract & 2 \\
Uncertain & 1 \\
Primary CNS & $11(22 \%)$ \\
PNET & 7 \\
Glioma & 1 \\
Lymphoma & 1 \\
Germinoma & 1 \\
"Pinealoma" & 1 \\
Haemopoietic & $10(20 \%)$ \\
Leukaemia & 6 \\
Lymphoma & 4 \\
Melanoma & $3(6 \%)$ \\
Seminoma & $1(2 \%)$ \\
\hline
\end{tabular}

Table 2 Clinical diagnosis at time of CSF sampling (malignancy subsequently confirmed)

\begin{tabular}{ll}
\hline Clinical diagnosis & Number (confirmed) \\
\hline Malignant meningitis & 50 \\
Known primary & 43 \\
Suspected primary & $7(4)$ \\
Tuberculous meningitis & $2(2)$ \\
Benign intracranial hypertension & $1(1)$ \\
Headache/arachnoid cyst & 1 \\
\hline
\end{tabular}

clinically diagnosed as malignant meningitis, and subsequently lost to follow up, one of whom had a normal chest $x$ ray and bronchoscopy. The final patient was well when discharged from follow up 26 months after a cytological diagnosis of carcinomatous meningitis. This seems to be the only false positive diagnosis.

TYPE OF MALIGNANCY

Half of definite malignancies were carcinomas, mostly adenocarcinomas of the breast or lung (table 1 ). Of the $22 \%$ which were primary central nervous system (CNS) malignancies, most were primitive neuroectodermal tumours (PNETs), and CNS infiltration by acute lymphoblastic leukaemia was the commonest of the haemopoietic malignancies, which constituted $20 \%$ of the total. Other malignancies were rare.

CLINICAL DIAGNOSIS

At the time of CSF sampling most (50/54) of the patients whose CSF contained malignant cells on cytological examination were thought to have malignant meningitis and 43 of these already had a known primary (table 2 ). Malignancy was subsequently confirmed in four.

Of those not thought clinically to have malignant meningitis, two were diagnosed as tuberculous meningitis and one as benign intracranial hypertension, all of whom were subsequently found to have a malignancyPNET in two cases and a bronchial carcinoma in one. A fourth, the false positive case, had headache and an arachnoid cyst.

\section{ANALYSIS OF CELL COUNTS AND PROTEIN CONCENTRATIONS}

CSF cell counts and protein measurements were available for 29 patients with malignant cells identified cytologically, 26 of whom had proven malignancy (table 3 ). The vast majority $(21 / 26)$ had a raised cell count and protein concentration (normal cell count $<5 / \mathrm{mm}^{3}$ after correction for blood contamination ${ }^{7}$ : protein $<0.4 \mathrm{~g} / \mathrm{l})$. In only one case were those parameters normal and she was strongly suspected of having malignancy at the time of CSF sampling. All of the patients not suspected of having malignancy at the time of sampling had a raised cell count or protein concentration, or both.

Therefore, all of the cases with malignant cells in the CSF fulfilled at least one of the following criteria: clinically known or suspected malignancy; raised cell count; raised protein concentration. In practice, most had all three.

REVIEW OF CASES IN WHICH CYTOLOGY WAS NOT CARRIED OUT

Of the 100 cases reviewed in which cytology had not been carried out on the basis of these criteria, only two had malignancy at the time of CSF sampling (carcinoma of the head of the pancreas; multiple myeloma) and one subsequently developed it (carcinoma of breast two years later). There was no evidence in any of these cases that the malignancy involved the CSF pathways at any time or that malignant cells could have been present in the CSF and missed by not carrying out CSF cytology.

\section{Discussion}

In only one of the 54 patients whose CSF contained cytologically malignant cells does the diagnosis seem to have been wrong. It is highly unlikely that a patient with carcinomatous meningitis would be symptom-free and well 26 months after his initial presentation.

Although 50 patients with CSF malignant cells were thought clinically to have malignant meningitis at the time of CSF sampling, 43 of whom already had a known primary malignancy, there was a small, but highly important, group of patients in whom the diagnosis was not suspected. Two of these were thought to have tuberculous meningitis and one, benign intracranial hypertension. One of the former subsequently developed a bronchial carcinoma and the others, PNETs.

Any system of selection of CSF for cytology in the laboratory must ensure that, whilst mini-

Table 3 Cell count and protein concentration in patients with confirmed malignancy and in whom malignancy was, or was not, suspected clinically at the time of CSF sampling

\begin{tabular}{llllll}
\hline Malignancy & Total & Raised cell count & $\begin{array}{l}\text { Raised protein } \\
\text { concentration }\end{array}$ & $\begin{array}{l}\text { Raised cell count } \\
\text { and protein } \\
\text { concentration }\end{array}$ & Normal \\
\hline Confirmed & 26 & 1 & 3 & 21 & 1 \\
Suspected & 26 & 2 & 2 & 21 & 1 \\
Unsuspected & 3 & 0 & 1 & 2 & 0 \\
\hline
\end{tabular}


mising unnecessary procedures, patients with malignant meningitis, in whom the diagnosis is not suspected clinically, are not missed. The CSF cell count and protein are useful screening procedures in this respect. In the present study, only one patient had a normal cell count and protein concentration and she was strongly suspected, on clinical and radiological grounds, of having malignancy involving the CNS. None of the patients in whom the diagnosis of malignancy was not suspected clinically had a normal cell count and protein concentration. In other words, all patients with malignant cells in the CSF fulfilled at least one of the following criteria: clinically known or suspected malignancy; raised CSF cell count; raised CSF protein concentration; and, in practice, most fulfilled all three. This is in accord with the results of Hayward et al who found that all of their 52 patients with malignant meningitis had at least a raised cell count or protein concentration or opening CSF pressure. CSF cytology is mandatory in all cases of known, or strongly suspected, malignancy. This is particularly true in cases of leukaemia and lymphoma, where the results of CSF cell counts and cytology are important factors in determining and monitoring treatment. However, selection of cases without known or suspected malignancy may be undertaken on the basis of CSF cell count and protein; if both are normal, then malignant cells are almost certainly not present and cytology is unnecessary, a conclusion corroborated by the fact that no cases of malignant meningitis were identified in the 100 cases reviewed in the present study.

It is acknowledged that although such a policy reduces the number of unnecessary CSF cytological examinations, some of the examinations undertaken on CSF from patients not thought to have malignancy will still be valueless. Further selection of samples for cytology can be made on the basis of clinical information-for example, cytology is unnecessary, even if the cell count and protein concentration are raised, if the patient has recently undergone an invasive neurosurgical procedure for a non-neoplastic lesion or if there is a clear clinical history of multiple sclerosis or subarachnoid haemorrhage.
It should be possible to select cases for CSF cytology on the basis of cell count and protein concentration, where cytopathology or neuropathology departments are closely related to chemical pathology and microbiology departments, or where information technology is shared. In light of the increasing drive towards "market testing" of pathology services, ${ }^{8}$ reducing unnecessary CSF cytology is one way in which cytopathology and neuropathology providers can reduce their costs.

In conclusion, this study has provided some criteria by which the laboratory may decide when CSF cytology is likely to be of value, and so minimise the number of profitless CSF cytological examinations, whilst ensuring that patients with suspected or unsuspected malignant meningitis are correctly diagnosed and managed.

\section{Addendum}

Since completion of this study, another patient was encountered in whom the diagnosis of malignant meningitis was not suspected clinically. Cytokeratin and epithelial membrane antigen positive malignant cells were identified in the CSF on two separate occasions, despite a clinical diagnosis of benign intracranial hypertension. However, the CSF protein concentration and cell count were both raised at $0.82 \mathrm{~g} / \mathrm{l}$ and 156 white cells $/ \mathrm{mm}^{3}$, respectively.

The following are gratefully acknowledged: the secretarial assistance of Mrs A M M Ross; the supply of histological material by Drs M T Haqqani, W Taylor, D $M$ Wayte, and H D Zakhour.

1 Health and Public Policy Committee, American College of Physicians. The diagnostic spinal tap. Ann Intern Med 1986;104:880-5.

2 Marton KI, Gean AD. The spinal tap: a new look at an old test. Ann Intern Med 1986; 104:840-8.

3 Fairbanks VF, Folger WN. Cost containment, quality assurance and physician microscopy of cerebrospinal fluid with normal cell counts. Am F Clin Pathol 1990;94:67-72.

4 Hayward RA, Shapiro MF, Oye RK. Laboratory testing on cerebrospinal fluid. A reappraisal. Lancet 1987;i: 1 -4.

5 Andrews JM, Schumann GB. Neurocytopathology. Baltimore: Williams and Wilkins, 1992:25-7.

6 Bigner SH, Johnston WW. Cytopathology of the central nervous system. London: Edward Arnold, 1994:33-57.

7 Conly JM, Ronald AR. Cerebrospinal fluid as a diagnostic fluid. Am ₹ Med 1983;75:102-8.

8 HMSO. Strategic review of pathology services. London: HMSO, 1995. 